Submitted to: Surface Science

Date: $11 / 16 / 2105$

\title{
A New Form of Chemisorbed Photo- and Electro-Active Atomic H Species on the $\mathrm{TiO}_{2}(110)$ Surface
}

\author{
Zhen Zhang ${ }^{*}$, and John T. Yates, Jr. \\ *Department of Chemistry, University of Virginia, Charlottesville, VA 22904 \\ *Correspondence to: zhangzhenchem@gmail.com
}




\begin{abstract}
Hydrogen adsorption on $\mathrm{TiO}_{2}$ is of importance in chemical and photochemical reduction processes. Using several surface science methods, we clearly distinguish two kinds of $\mathrm{H}$ species on the surface of rutile $\mathrm{TiO}_{2}(110)-1 \times 1$. In contrast with the well-studied bridgebonded $\mathrm{OH}$ species $(\alpha-\mathrm{H})$ originating from $\mathrm{H}_{2} \mathrm{O}$ dissociation on the surface oxygen vacancy site on $\mathrm{TiO}_{2}(110)$, atomic $\mathrm{H}$ adsorption on the $\mathrm{TiO}_{2}(110)$ (denoted as $\beta-\mathrm{H}$ ) exhibits special high sensitivity to the electronic excitation of the $\mathrm{TiO}_{2}(110)$ by either electrons or UV photons. The formation of molecular $\mathrm{H}_{2}$ gas by photoexcitation of $\beta$ $\mathrm{H} / \mathrm{TiO}_{2}(110)$ surfaces has been observed, which may shed light on the basic understanding of the processes of photocatlytic $\mathrm{H}_{2}$ production by splitting water.
\end{abstract}

\title{
Keywords:
}

Electron stimulated desorption, $\mathrm{TiO}_{2}(110), \mathrm{H}_{2} \mathrm{O}$, Atomic $\mathrm{H}$ 


\section{Introduction}

Chemisorbed $\mathrm{H}$ species play important roles in the wide applications of metal oxides in the fields of catalysis ${ }^{1,2}$, photocatalysis ${ }^{3,4}$ and electronics ${ }^{5,6}$. Surface-bound atomic hydrogen, $\mathrm{H} / \mathrm{TiO}_{2}$, should be centrally important in solar-driven chemical reduction processes of the future such as for the production of useful hydrogenated organic products from $\mathrm{CO}_{2}{ }^{7}$ as well as $\mathrm{H}_{2}$ from $\mathrm{H}_{2} \mathrm{O}^{3,8}$. Such photochemical reduction processes involving $\mathrm{H} / \mathrm{TiO}_{2}$ species will become important in the future capture, storage and transport of solar energy as fuels. Also in heterogeneous catalysis, atomic $\mathrm{H}$ spilled over from $\mathrm{H}_{2}$ dissociation from supported metals and stabilized on metal oxides, such as $\mathrm{TiO}_{2}$, is important in surface reduction processes even in the absence of light activation. ${ }^{1}$ Additionally, the absorption of $\mathrm{H}$ in $\mathrm{TiO}_{2}$ crystals significantly changes the $\mathrm{TiO}_{2}$ geometric and electronic structure, increasing the solar light absorption efficiency and photocatalytic activity. ${ }^{3,4,9}$

The rutile- $\mathrm{TiO}_{2}(110)$ surface is the prototype oxide surface, widely studied as a model photocatalytic material (band gap $=3.1 \mathrm{eV}$ ) as well as a model support for metallic catalyst particles. ${ }^{10-13}$ It is a reducible oxide which may be partially reduced by heating in vacuum to $\sim 900 \mathrm{~K}$, exhibiting up to $\sim 10 \%$ bridge-bonded oxygen vacancy (BBOV) defects at the surface. ${ }^{14}$ Several possible $\mathrm{H}$ adsorption configurations have been studied by DFT calculations ${ }^{15-17}$ on both the stoichiometric $\mathrm{TiO}_{2}(110)$ and reduced $\mathrm{TiO}_{2}(110)$ surfaces with BBOV sites. As shown in the inset of Figure 1, five energetically favorable $\mathrm{H}$ adsorption sites relative to gas phase atomic $\mathrm{H}$ on the top of $\mathrm{TiO}_{2}(110)$ surfaces have been suggested: (1). $\mathrm{H}$ on the BBO sites ( $\alpha$-H species); (2). $\mathrm{H}$ on the in-plane $\mathrm{O}$ sites; (3). $\mathrm{H}$ on the BBOV sites; (4). H on the Ti5c sites; (5) $\mathrm{H}$ near the subsurface $\mathrm{O}$ sites.

So far, the most experimentally studied $\mathrm{H}$ species on $\mathrm{TiO}_{2}(110)$ is $\alpha-\mathrm{H}$, which can be made from water adsorption at BBOV defects producing $2 \mathrm{OH}$ species per adsorbed $\mathrm{H}_{2} \mathrm{O}$ molecule on the bridge-bonded oxygen (BBO) sites. ${ }^{18-20}$ It has been detected by surface science methods, such as the vibrational spectroscopies, ${ }^{21}$ scanning tunneling microscopy (STM), ${ }^{19,20,22,23}$ photoelectron spectroscopy (PES) ${ }^{22}$, electron stimulated desorption (ESD) and temperature programmed desorption 
(TPD). ${ }^{21,24}$ The influence of $\alpha-\mathrm{H}$ groups on the surface electronic structures and chemical behaviors on $\mathrm{TiO}_{2}(110)$ surfaces has also been studied. ${ }^{2,24}$

Besides the well-studied $\alpha-\mathrm{H}$ groups, there are other adsorbed $\mathrm{H}$ species proposed which have also been involved in photochemical/chemical processes on $\mathrm{TiO}_{2}$. Absorbed atomic $\mathrm{H}$ in the $\mathrm{TiO}_{2}$ lattice has previously been shown to result in the production of electronic states near the bottom of the conduction band which can be excited by IR radiation into continuum states in the conduction band of $\mathrm{TiO}_{2}{ }^{25,26}$ Similar results are reported also for $\mathrm{ZnO} .{ }^{27}$ Recently a rather unstable form of bound hydrogen was produced electrochemically on a $\mathrm{TiO}_{2}(001)$ crystal cathode and was found to migrate into the bulk of the $\mathrm{TiO}_{2}{ }^{28}$ This hydrogenic species can be removed by exposure to air at $300 \mathrm{~K}$. Atomic $\mathrm{H}$ produced electrochemically on $\mathrm{Nb}_{2} \mathrm{O}_{5}$ and on $\mathrm{WO}_{3}$ was reported to reduce $\mathrm{Cu}^{2+}(\mathrm{aq})$ to $\mathrm{Cu}$ metal. ${ }^{28}$ All of these observations combined lead to the viewpoint that atomic $\mathrm{H}$ may be stabilized on $\mathrm{TiO}_{2}$ and other oxide surfaces in a manner involving a new type of adsorbed $\mathrm{H}$ and that it can act as a powerful reducing agent. Compared with the well-known $\alpha-\mathrm{H}$ species, these $\mathrm{H}$ species have not been well studied by surface science methods and still remain elusive. ${ }^{15,29,30}$

Here we show that a new form of atomic $\mathrm{H}$ species (denoted as $\beta-\mathrm{H}$ ) can be stabilized on $\mathrm{TiO}_{2}(110)$ surface. The species is chemically distinct from the wellknown $\mathrm{H}_{2} \mathrm{O}$-produced surface $\alpha-\mathrm{H}$ groups on the bridge-bonded oxygen (BBO) rows, and one of its distinguishing properties is that it can be efficiently activated both by electrons and UV photons. In photocatalytic and catalytic processes on $\mathrm{TiO}_{2}$, this $\beta$ $\mathrm{H} / \mathrm{TiO}_{2}$ species may act as strong reducing agent, which can affect the surface chemistry of $\mathrm{TiO}_{2}$.

\section{Experimental}

All the experiments were carried out in a stainless-steel ultrahigh vacuum chamber (base pressure below $3 \times 10^{-11}$ mbar). A clean $\mathrm{TiO}_{2}(110)$ surface (Princeton Scientific, 7 $\mathrm{mm} \times 7 \mathrm{~mm} \times 1 \mathrm{~mm}$ ) with $\sim 8 \% \mathrm{BBOV}$ (in dark-blue color) was prepared by cycles of $\mathrm{Ar}^{+}$sputtering and annealing at $950 \mathrm{~K}$. The cleanliness and $1 \times 1$ structure of the crystal have been tested by Auger electron spectroscopy and low-energy electron diffraction 
apparatus. Atomic H/D were generated by dissociation of $\mathrm{H}_{2} / \mathrm{D}_{2}\left(\mathrm{P}_{\mathrm{H} 2 / \mathrm{D} 2}=1 \times 10^{-7} \mathrm{mbar}\right)$ on a hot $\mathrm{W}$ filament producing $\beta-\mathrm{H}$ or $\beta-\mathrm{D} / \mathrm{TiO}_{2}$ species on $\mathrm{TiO}_{2}(110)$ at $90 \mathrm{~K}$. Water vapor was exposed to the $\mathrm{TiO}_{2}(110)$ surface at $320 \mathrm{~K}$ producing $\alpha-\mathrm{H} / \mathrm{TiO}_{2}(110)$ surface by water dissociation on BBOV sites. $210 \mathrm{eV}$ electron bombardment of single crystal surfaces at $83 \mathrm{~K}$ to cause electron stimulated desorption (ESD) has been used here to characterize the chemisorbed $\mathrm{H}$ species on $\mathrm{TiO}_{2}(110)$ by the observation of the $\mathrm{H}^{+}$ fragment product. We have used time-of-flight $\mathrm{H}^{+}$electron stimulated desorption, the $\mathrm{H}^{+}$ ion angular distributions by TOF-ESDIAD (time-of-flight electron stimulated desorption ion angular distribution) and the measurement of total cross section for ESD to characterize the new form of surface $\beta-\mathrm{H}$, and to clearly distinguish it from the wellknown surface $\alpha-\mathrm{H}$ species. The $\mathrm{H}^{+}$angular distribution often relates simply to the chemical bond directions when ESD-induced bond dissociation and ionization result in a Coulomb explosion. Deflection of $\mathrm{H}^{+}$ions by final state effects can also influence ESDIAD ion angular distributions. ${ }^{31,32}$ The UV light from a broad-band Hg lamp with a IR filter was transferred to the sample by a fiber optic cable with $1.4 \times 10^{-3} \mathrm{~W} / \mathrm{cm}^{2}$ in the photon energy range 1.1-5.4 eV during the full spectrum UV exposure experiment. Sometimes, a $395 \mathrm{~nm}$ bandpass filter was used to get UV photons with $3.4 \pm 0.1 \mathrm{eV}$ energy $\left(F_{h v}=2.5 \times 10^{14}\right.$ photons $\left.\mathrm{cm}^{-2} \mathrm{~s}^{-1}\right)$ for the UV experiments indicated in the text. The UV exposure does not influence the sample temperature notably (less than $\sim 0.1 \mathrm{~K}$ ).

\section{Results and Discussion}

Using $210 \mathrm{eV}$ electrons and a pulse-counting ion angular distribution apparatus, it is found that $\alpha-\mathrm{H}$ species from adsorbed $\mathrm{OH}$ (from sub-monolayer (ML) $\mathrm{H}_{2} \mathrm{O}$ adsorption) and from atomic $\mathrm{H}$ adsorption $(\beta-\mathrm{H})$ on $\mathrm{TiO}_{2}(110)$ yield almost identical $\mathrm{H}^{+}$time-of-flight (TOF) distributions, as shown in Figure 1. The $0.5 \mu$ s flight time, corrected for ion acceleration in the apparatus, corresponds to an $\mathrm{H}^{+}$kinetic energy for ion ejection of $9 \pm 3 \mathrm{eV}$ for ESD from both $\alpha-\mathrm{H}$ and $\beta$-H adsorbed species. While the ion energies are very similar, the ion angular distributions for $\alpha-\mathrm{H}$ and $\beta-\mathrm{H}$ differ significantly as shown in Figure $2 \mathrm{~A}-\mathrm{B} . \quad \beta-\mathrm{H} / \mathrm{TiO}_{2}$ yields an almost circularly symmetric, normally-oriented $\mathrm{H}^{+}$angular distribution while $\alpha-\mathrm{H} / \mathrm{TiO} \mathrm{O}_{2}$ yields a highly elongated $\mathrm{H}^{+}$angular distribution. The elongation of the angular distribution of $\mathrm{H}^{+}$ 
from $\alpha-\mathrm{H} / \mathrm{TiO}_{2}$ is in the $[1 \overline{1} 0]$ direction perpendicular to the rows of bridge-bonded $\mathrm{O}$ atoms on the outer surface, as shown in the insert to Figure $2 \mathrm{~B}$. The elongated $\mathrm{H}^{+}$ ESDIAD pattern for $\alpha-\mathrm{H} / \mathrm{TiO}_{2}$ indicates that the $\mathrm{O}-\mathrm{H}$ bonds are inclined to the left or right in the [1 $\overline{1} 0]$ direction as has been suggested by DFT calculations, ${ }^{17}$ or alternatively that high amplitude $\mathrm{OH}$ bending modes are present. ${ }^{33}$

The thermal properties of the $\beta-\mathrm{H}$ and $\alpha-\mathrm{H}$ species differ greatly as shown in Figure $2 \mathrm{C}-\mathrm{D}$. Here we use the time- and angle-integrated yield of $\mathrm{H}^{+}$by ESD as a probe for study of the coverage of the two surface hydrogenic species as temperature is increased in vacuum. (Low electron flux of $0.31 \times 10^{10} \mathrm{e} \mathrm{cm}^{-2} \mathrm{~s}^{-1}$ and short exposing time of 30s has been chosen during the measurement to diminish the ESD effect of $\mathrm{H}$ depletion by incident electrons, as been discussed below in Figure 3.) For $\beta-\mathrm{H} / \mathrm{TiO}_{2}$ species, depletion by heating in vacuum occurs already below $350 \mathrm{~K}$, as shown in Figure 2C. Following $\beta-\mathrm{H} / \mathrm{TiO}_{2}$ depletion, a fractional ML remaining coverage of $\alpha-\mathrm{H} / \mathrm{TiO}_{2}$ (due to impurity $\mathrm{H}_{2} \mathrm{O}$ adsorption) is found to deplete above $\sim 350 \mathrm{~K}$. The $\alpha-\mathrm{H}$ species are inadvertently added to the surface during bombardment by atomic $\mathrm{H}$ from small quantities of $\mathrm{H}_{2} \mathrm{O}$ present in the ultrahigh vacuum chamber; this was excluded in an alternative atomic D experiment (Figure S1) where only a small amount of $\alpha$-D species are produced. When only $\mathrm{H}_{2} \mathrm{O}$ is adsorbed, to produce only $\alpha-\mathrm{H} / \mathrm{TiO}_{2}$, the behavior of the $\alpha-\mathrm{H} / \mathrm{TiO}_{2}$ upon heating is shown in Figure 2D, showing that $\alpha-\mathrm{H} / \mathrm{TiO}_{2}$ thermal depletion occurs only above $\sim 350 \mathrm{~K}$. The thermal stability of $\alpha-\mathrm{H} / \mathrm{TiO}_{2}$ shown in Figure 2C-D exceeds that of $\beta-\mathrm{H} / \mathrm{TiO}{ }_{2}$, showing that the energy and structure of two kinds of surface hydrogen differ chemically. The thermal loss of $\alpha-\mathrm{H} / \mathrm{TiO}_{2}$ is accompanied by $\mathrm{H}_{2} \mathrm{O}$ desorption. ${ }^{24}$ The thermal desorption from $\beta-\mathrm{H} / \mathrm{TiO}_{2}$ has not been well described in this work. From the data in Figure $2 \mathrm{C}-\mathrm{D}$, we see that the saturation coverage of $\beta-\mathrm{H} / \mathrm{TiO}_{2}$ above the background due to $\alpha-\mathrm{H} / \mathrm{TiO}_{2}$ gives about $19 \times 10^{3} \mathrm{H}^{+} \mathrm{ESD}$ counts/30 s, whereas the saturation coverage of $\alpha-\mathrm{H} / \mathrm{TiO}_{2}$ gives about $33 \times 10^{3} \mathrm{H}^{+}$ESD counts/30 s. These count rates are consistent with those measured by integration in Figure 1.

The chemical difference between $\alpha$ - and $\beta-\mathrm{H} / \mathrm{TiO}_{2}$ is also vividly demonstrated by comparing their sensitivity to electron stimulated desorption. Figure 3 shows the almost complete lack of sensitivity of $\alpha-\mathrm{H} / \mathrm{TiO}_{2}$ to electron stimulated desorption $\left(\mathrm{V}_{\mathrm{e}}\right.$ 
$=210 \mathrm{eV}$ ) at an electron flux $\mathrm{F}_{\mathrm{e}}=6.25 \times 10^{10} \mathrm{e} \mathrm{cm}^{-2} \mathrm{~s}^{-1}$ at $83 \mathrm{~K}$. In contrast, for $\beta$ $\mathrm{H} / \mathrm{TiO}_{2}$, for $\mathrm{F}_{\mathrm{e}}$ in the range $0.31-3.13 \times 10^{10} \mathrm{e} \mathrm{cm}^{-2} \mathrm{~s}^{-1}$, a monotonically increasing and large rate of $\mathrm{H}$ depletion by ESD is observed. $\beta-\mathrm{H} / \mathrm{TiO}_{2}$ is very sensitive to electrons and responds both by ionization to produce $\mathrm{H}^{+}$and by the breaking of the $\mathrm{X}-\mathrm{H}$ (X may be Ti or $\mathrm{O}$ ) bond by incident electrons (presumably to yield desorbing $\mathrm{H})$. The data shown in Figure 3 are combined to determine the $\beta-\mathrm{H} / \mathrm{TiO}_{2}$ total desorption cross section during ESD. A total cross section of $\mathrm{Q}=\sim 7 \times 10^{-14} \mathrm{~cm}^{2}$ is found (Figure S2). This very large total cross section (which exceeds typical molecular cross sections by a factor of $\sim 100$ or more) indicates that multiple elementary electronic excitation events occur in $\mathrm{TiO}_{2}$ during $210 \mathrm{eV}$ electron bombardment of the $\mathrm{TiO}_{2}$ semiconductor surface; the $\mathrm{H}$ atoms from the $\beta-\mathrm{H} / \mathrm{TiO}_{2}$ species probably desorb by excitation processes involving the production of multiple charge carriers per incident $210 \mathrm{eV}$ electron in the $\mathrm{TiO}_{2}$. In contrast to the very high cross section for $\beta-\mathrm{H} / \mathrm{TiO}_{2}$, the total cross section for $\alpha-\mathrm{H} / \mathrm{TiO}_{2}$ destruction by ESD is estimated to be only $\sim 10^{-20} \mathrm{~cm}^{2}$, a more-normal total ESD-cross section. ${ }^{31}$ This large $\sim 5$ order of magnitude difference in total cross section for ESD of $\mathrm{H}$ from $\alpha$ - and $\beta$ $\mathrm{H} / \mathrm{TiO}_{2}$ further supports the concept of a large chemical difference between the two kinds of bound $\mathrm{H}$ on the $\mathrm{TiO}_{2}(110)$ surface.

The influence of UV irradiation on the $\mathrm{H} / \mathrm{TiO}_{2}$ species has also been investigated by monitoring the $\mathrm{H}^{+}$-ESD yield at low electron bombardment rate during UV irradiation. Using (for $\mathrm{H}$ coverage measurement) the ESD production of $\mathrm{H}^{+}$from $\mathrm{H} / \mathrm{TiO}_{2}$ (at $\mathrm{F}_{\mathrm{e}}=0.31 \times 10^{10} \mathrm{e} \mathrm{cm}^{-2} \mathrm{~s}^{-1}$, which is too low to cause significant depletion of $\beta-\mathrm{H}$ by incident electrons in the measurements), it is seen that $\beta-\mathrm{H} / \mathrm{TiO}_{2}$ species are also able to be desorbed by UV photons of $3.4 \pm 0.1 \mathrm{eV}$ energy, just above the $\mathrm{TiO}_{2}$ bandgap. Figure 4 shows the effect of UV irradiation on $\beta-\mathrm{H} / \mathrm{TiO}_{2}$ coverage. It may be seen that an exponential decay is observed, and that by $\sim 5 \times 10^{16}$ photons $\mathrm{cm}^{-2}$ exposure, all $\beta-\mathrm{H} / \mathrm{TiO}_{2}$ species have been desorbed by UV irradiation. A control experiment in the dark does not lead to depletion of $\mathrm{H}$ species and in addition $\alpha$ $\mathrm{H} / \mathrm{TiO}_{2}$ is found to be insensitive to UV photons (Figure S3), which agrees with previous experiments ${ }^{34-36}$. At the red arrow in Figure 4, about $50 \mathrm{ML}$ of $3.4 \mathrm{eV}$ photons have completely removed the $\beta-\mathrm{H} / \mathrm{TiO}_{2}$ monolayer. The large total 
photodesorption cross section $\left(\sim 10^{-16} \mathrm{~cm}^{2}\right)$ for $\beta-\mathrm{H} / \mathrm{TiO}_{2}$ is $\sim 10^{-3}$ that of the very high total cross section of the ESD process caused by $210 \mathrm{eV}$ electrons for $\beta-\mathrm{H} / \mathrm{TiO}_{2}$ (Figure S2). It is clear that $\beta-\mathrm{H} / \mathrm{TiO}_{2}$ is very sensitive to electronic excitation either by electrons or by $3.4 \mathrm{eV}$ photons, whereas $\alpha-\mathrm{H} / \mathrm{TiO}_{2}$ is orders of magnitude less able to be desorbed or ionized by electrons or photons.

The depletion product of $\beta-\mathrm{H} / \mathrm{TiO}_{2}$ irradiated by UV light has also been detected by QMS. To exclude the influence of high background of $\mathrm{H}_{2}$ during QMS measurements, alternative atomic $\mathrm{D}$ has been exposed to $\mathrm{TiO}_{2}(110)$ instead of atomic $\mathrm{H}$. Figure 5 shows the desorption of $\mathrm{D}_{2}$ from $\beta$-D/TiO ${ }_{2}$ surfaces excited by UV photons. Similar to the previous $\mathrm{O}_{2}$ photodesorption experiment on $\mathrm{O}_{2}$-exposed $\mathrm{TiO}_{2}(110)$ surfaces, ${ }^{37} \mathrm{D}_{2}$ signal quickly reached the maximum within the first 0.2-0.4 $s$ after the UV light is on and monotonically decreased over time due to the depletion of $\beta$-D/TiO 2 species. The time-of-flight spectra of $\mathrm{D}^{+}$(Fgure S4) produced by lowelectron bombardment from $\beta-\mathrm{D} / \mathrm{TiO}_{2}$ surface before and after UV irradiation have shown that almost all the $\beta$-D species have been removed upon UV irradiation, which agrees with Figure 4 . The photo yield of $\mathrm{D}_{2}$ increases with the $\beta-\mathrm{D} / \mathrm{TiO} \mathrm{O}_{2}$ adsorption by increasing the atomic $\mathrm{D}$ exposing time, as shown in Figure 5B. The direct observation of photochemical molecular $\mathrm{D}_{2}$ formation from $\beta-\mathrm{D} / \mathrm{TiO}_{2}$ surface is very important in understanding the processes of hydrogen production from photo splitting of water on $\mathrm{TiO}_{2}$-based materials. This has never been observed on single crystal surface study of $\mathrm{TiO}_{2}$ until a recent study by $\mathrm{Wu}$ et al. ${ }^{16}$ Further studies are needed to explore the detailed mechanism of $\mathrm{D}_{2}$ production in the future.

The above experimental results therefore indicate that the $\beta-\mathrm{H} / \mathrm{TiO}_{2}$ species have low thermal stability and extremely high sensitivity to incident electronic excitation by electrons and photons, which is completely opposite to the behavior of the $\alpha-\mathrm{H}$ species. However, the exact location of $\beta-\mathrm{H}$ species on $\mathrm{TiO}_{2}(110)$ cannot be directly determined in this experiment. Table 1 summarized the calculated binding energies of different energy sites of $\mathrm{H}$ on $\mathrm{TiO}_{2}(110)$ (relative to $\mathrm{H}$ atoms) from previous publications. ${ }^{15-17}$ On the stoichiometric $\mathrm{TiO}_{2}(110)$ surface, $\mathrm{H}$ on $\mathrm{BBO}$ site $(\alpha-\mathrm{H})$ is more stable than $\mathrm{H}$ on the in-plane $\mathrm{O}$ site while $\mathrm{H}$ on the Ti5c site is not energetically stable. Meanwhile, $\mathrm{H}$ can also diffuse into the bulk forming subsurface hydroxyl 
species. ${ }^{15}$ However, on the highly defective surface $(\mathrm{BBOV} \%=0.25 \mathrm{ML}), \mathrm{Wu}$ et $a l .{ }^{16}$ found that $\mathrm{H}$ on the BBOV site has almost the same binding energy as $\alpha-\mathrm{H}$ species. Our experimental results generally agree with the previous DFT calculation results indicating that the $\alpha-\mathrm{H}$ species is more energetically favorable than other $\mathrm{H}$ species.

Based on our experimental results and the previous theoretical work, ${ }^{15-17}$ we speculate the possible $\beta-\mathrm{H}$ configuration is $\mathrm{H}$ near subsurface $\mathrm{O}$ (subsurface hydroxyl) sites: (1). The control experiments of $\alpha-\mathrm{H} / \mathrm{TiO}_{2}$ species shows significantly different activity of thermal and photo- and electron- stimulated losses compared to $\beta-\mathrm{H} / \mathrm{TiO}_{2}$. That means atomic $\mathrm{H}$ does not adsorb on the $\mathrm{BBO}$ site. (2). $\mathrm{H}$ on BBOV sites has been excluded. The binding energy of $\mathrm{H}$ on BBOV site is similar to the $\alpha$ $\mathrm{H} / \mathrm{TiO}_{2}$ species, which contradicts the thermal experiment in Figure 2. ${ }^{16}$ The new $\mathrm{H} / \mathrm{TiO}_{2}$ species is reduced by only $50 \%$ in its saturation coverage by filling the oxygen vacancies with preadsorbed $\alpha-\mathrm{H} / \mathrm{TiO}_{2}$ groups (data not shown), which excludes BBOV sites as being directly responsible for the new $\mathrm{H} / \mathrm{TiO}_{2}$ species. (Full occupancy of BBOV sites by BBOH $(\alpha-\mathrm{H})$ species would result in a $100 \%$ reduction of $\mathrm{H} / \mathrm{TiO}_{2}$ capacity if these sites were specifically involved in $\mathrm{H} / \mathrm{TiO}_{2}$ bonding.) (3). While DFT calculations indicate that $\mathrm{H}$ on the in-plane $\mathrm{O}$ atom is energetically possible, ${ }^{15-17}$ the calculated diffusion energy barrier for $\mathrm{H}$ migration from in-plane $\mathrm{O}$ to $\mathrm{BBO}$ sites is very low (below $\sim 0.3 \mathrm{eV}$ ), ${ }^{38,39}$ which makes the stabilized $\mathrm{H}$ adsorption configuration on in-plane $\mathrm{O}$ less possible. (4). It is less likely that $\beta$ $\mathrm{H} / \mathrm{TiO}_{2}$ is the $\mathrm{H}$ on Ti5c sites. DFT calculations indicated that the $\mathrm{H}$ adsorption on Ti5c sites is not stable on stoichiometric $\mathrm{TiO}_{2}(110)$ surface and can only occur at highly defective surface with $25 \%$ BBOV concentration. ${ }^{16}$ Such a highly-reduced $\mathrm{TiO}_{2}(110)$ surface would not have $(1 \times 1)$ structure and is not irrelevant to current study. The presence of $\mathrm{H}$ on Ti5c sites had been observed using low-energy ion scattering spectroscopy by Pan et al. ${ }^{30}$ at room temperature (RT). However, the recent HREELS and TPD experiments by Yin et al. ${ }^{15}$ denied the presence of Ti5c-H species by exposing atomic $\mathrm{H}$ to $\mathrm{TiO}_{2}(110)$ at $\mathrm{RT}$. (5). $\beta-\mathrm{H} / \mathrm{TiO}_{2}$ may be the subsurface hydroxyl species formed by the diffusion of atomic $\mathrm{H}$ from the surface to the bulk. ${ }^{15,38,40,41} \mathrm{H}$ from the subsurface hydroxyl species can be excited in the form 
of $\mathrm{H}^{+}$by electrons and transports through surface layer and desorbs. ${ }^{42,43}$ Even though the binding energy of subsurface hydroxyl species is similar to $\alpha-\mathrm{H}$ species, the migration energy barrier $(\sim 1 \mathrm{eV})$ of subsurface hydroxyl species further into the bulk is notably lower. ${ }^{15,17}$ The less thermal stability of new $\beta-\mathrm{H}$ species observed in Figure 2 may be due to the deeper diffusion of subsurface $\mathrm{H}$ species upon annealing.

The detailed mechanism of electron- and UV-induced depletion of $\beta-\mathrm{H}$ on $\mathrm{TiO}_{2}(110)$ still has not been well understood. For $\alpha-\mathrm{H}$ species on $\mathrm{TiO}_{2}(110)$, electrons can excite $\alpha-\mathrm{H}$ species producing $\mathrm{H}^{+}$with a threshold energy of $22 \mathrm{eV}$, which is near to the $\mathrm{O} 2 \mathrm{~s}$ level. The desorption mechanism, which involves the creation of $\mathrm{O} 2 \mathrm{~s}$ holes and subsequent Auger decay processes, has been proposed by Knotek and Feibelman. ${ }^{44}$ In Figure 1, the desorbed $\mathrm{H}^{+}$ions by electron excitation from both $\alpha-\mathrm{H}$ and $\beta-\mathrm{H}$ species have similar kinetic energies, which may indicate that the ESD $\mathrm{H}^{+}$processes from both $\alpha-\mathrm{H}$ and $\beta-\mathrm{H}$ species follow the same mechanism and have similar $\mathrm{H}^{+}$ESD cross section. The large depletion rates (total cross section) of $\beta-\mathrm{H}$ species in Figure 3 may be due to the production of atomic $\mathrm{H}$ and/or $\mathrm{H}_{2}$ species by incident electrons. The QMS experiment in Figure 5 indicates the

production of $\mathrm{H}_{2}$ from $\beta-\mathrm{H}$ species. A recent work by Wu et al. ${ }^{16}$ also confirmed the production of $\mathrm{H}_{2}$ by UV irradiation of atomic $\mathrm{H}$ exposed $\mathrm{TiO}_{2}(110)$ surface. The authors speculated that the $\mathrm{H}_{2}$ production by UV irradiation is hole-mediated based upon their calculated $\mathrm{H}$ configuration on $\mathrm{TiO}_{2}$ surfaces. Further experiment and theoretical work are needed to understand the bonding mechanism of the $\beta-\mathrm{H}$ species and the mechanism of the electron and photon-induced $\mathrm{H}$ desorption.

\section{Conclusions}

In conclusion, a new type of surface $\mathrm{H}$ species $\left(\beta-\mathrm{H} / \mathrm{TiO}_{2}\right)$ have been prepared and identified on $\mathrm{TiO}_{2}(110)$ surfaces by dosing atomic $\mathrm{H}$. In comparison with the wellstudied $\alpha-\mathrm{H}$ species produced by $\mathrm{H}_{2} \mathrm{O}$ dissociation on $\mathrm{BBOV}$ sites, $\beta-\mathrm{H}$ presents different physical and chemical properties. It is less thermally stable and extremely sensitive to the incident electrons and $\mathrm{UV}$ photons compared to $\mathrm{H}_{2} \mathrm{O}$-derived $\alpha$ $\mathrm{H} / \mathrm{TiO}_{2} \cdot \beta-\mathrm{H}$ on $\mathrm{TiO}_{2}(110)$ can be excited by UV irradiation producing molecular $\mathrm{H}_{2}$ gas, which may shed light on the mechanism of photosplitting $\mathrm{H}_{2} \mathrm{O}$ producing $\mathrm{H}_{2}$. 
The direct ESD observation of the less stable $\beta-\mathrm{H}$ species on $\operatorname{TiO}_{2}(110)$ may also corroborate the previous proposal of highly mobile $\mathrm{H}$ species on metal oxide surfaces prepared by electrochemical hydrogenation ${ }^{28}$ or by spillover from supported metal clusters. ${ }^{1,45}$

The high electronic excitation sensitivity of $\beta-\mathrm{H} / \mathrm{TiO}_{2}$ species by incident electrons or UV photons and less thermal stability may be the reason of the ignorance of $\beta-\mathrm{H} / \mathrm{TiO}_{2}$ species in the previous surface science study. More experimental and theoretical studies are needed for a better understanding of this new $\mathrm{H}$ species.

\section{Acknowledgements:}

We acknowledge with thanks the support of DOE (DE-FG02-O9ER16080) for this work. We thank Prof. Ian Harrison, Prof. Horia Metiu, Dr. Henrik Kritoffersen, Prof. Charles T. Campbell, Prof. Jens Norskov, Dr. Aleksandra Vojvodic for helpful discussions. 
Table 1. Summary of binding energies $(\mathrm{eV})$ of $\mathrm{H}$ on $\mathrm{TiO}_{2}(110)$ surfaces (relative to $\mathrm{H}$ atoms) calculated by DFT calculations. $\left(\mathrm{s}-\mathrm{TiO}_{2}\right.$ : stoichiometrci $\mathrm{TiO}_{2} ; \mathrm{r}-\mathrm{TiO} 2$ : reduced $\left.\mathrm{TiO}_{2}\right)$.

\begin{tabular}{|c|c|c|c|c|}
\hline $\mathrm{H}$ adsorption sites & $\begin{array}{c}\text { s-TiO } \\
\text { (Ref. 15) }\end{array}$ & $\begin{array}{c}\text { s-TiO } \\
\text { (Ref. 17) }\end{array}$ & $\begin{array}{c}\mathrm{s}-\mathrm{TiO}_{2} \\
\text { (Ref. 16) }\end{array}$ & $\begin{array}{c}\mathrm{r}-\mathrm{TiO}_{2} \\
\text { (Ref. 16) }\end{array}$ \\
\hline BBO & -2.52 & -2.84 & -2.64 & -2.47 \\
\hline in-plane $\mathrm{O}$ & -1.76 & -2.22 & -2.19 & -1.90 \\
\hline $\mathrm{BBOV}$ & -- & -- & -- & $-2.47(-2.44)$ \\
\hline Ti5C & 0.01 & 0.06 & -0.07 & -1.17 \\
\hline subsurface $\mathrm{O}$ & -2.34 & -- & -- & -- \\
\hline
\end{tabular}




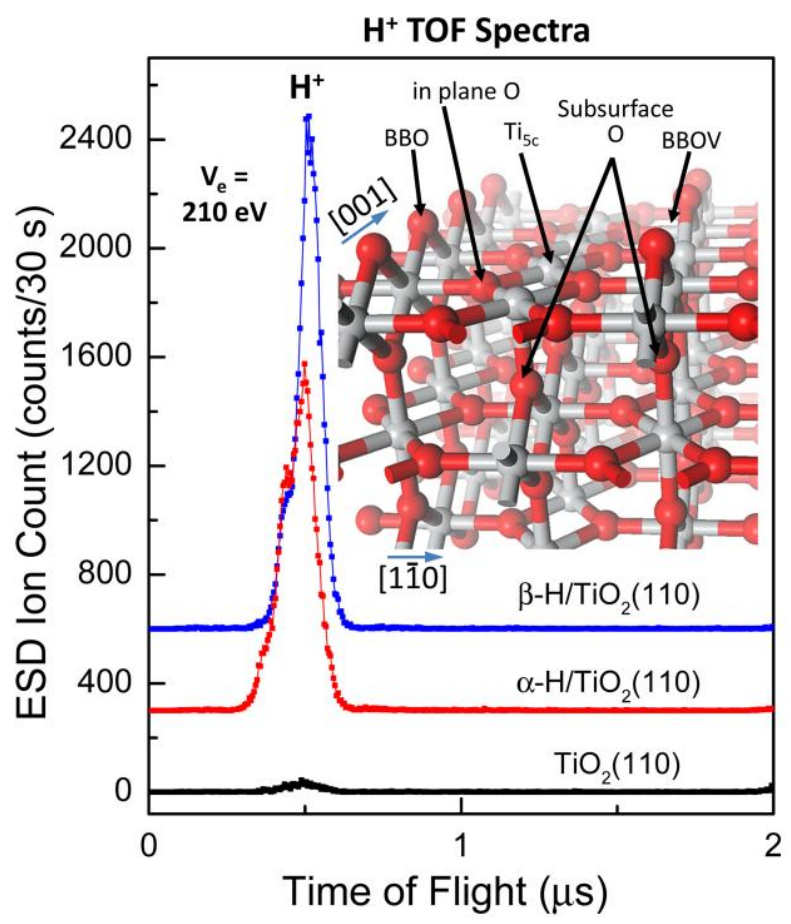

Figure 1. Time-of-flight spectra of $\mathrm{H}^{+}$produced by $210 \mathrm{eV}$ electron bombardment of on $\mathrm{TiO}_{2}(110), \alpha-\mathrm{H} / \mathrm{TiO}_{2}(110)$ and $\beta-\mathrm{H} / \mathrm{TiO}_{2}(110)$ surfaces. $\mathrm{F}_{\mathrm{e}}=6.25 \times 10^{10}$ electrons cm $\mathrm{cm}^{-2} \mathrm{~s}^{-}$ ${ }^{1}$. Inset shows the atomic structure of $\mathrm{TiO}_{2}(110)$ with bridge-bonded (BBOV) oxygen vacancy site. 
$\mathrm{H}^{+}$ESDIAD Patterns
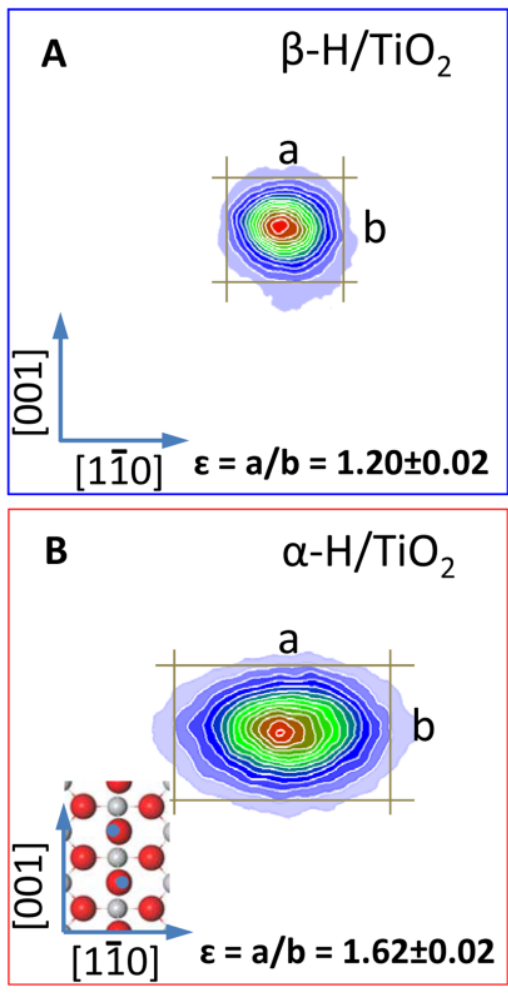

Thermal Behavior of $\alpha$ - and $\beta-\mathrm{H} / \mathrm{TiO}_{2}$
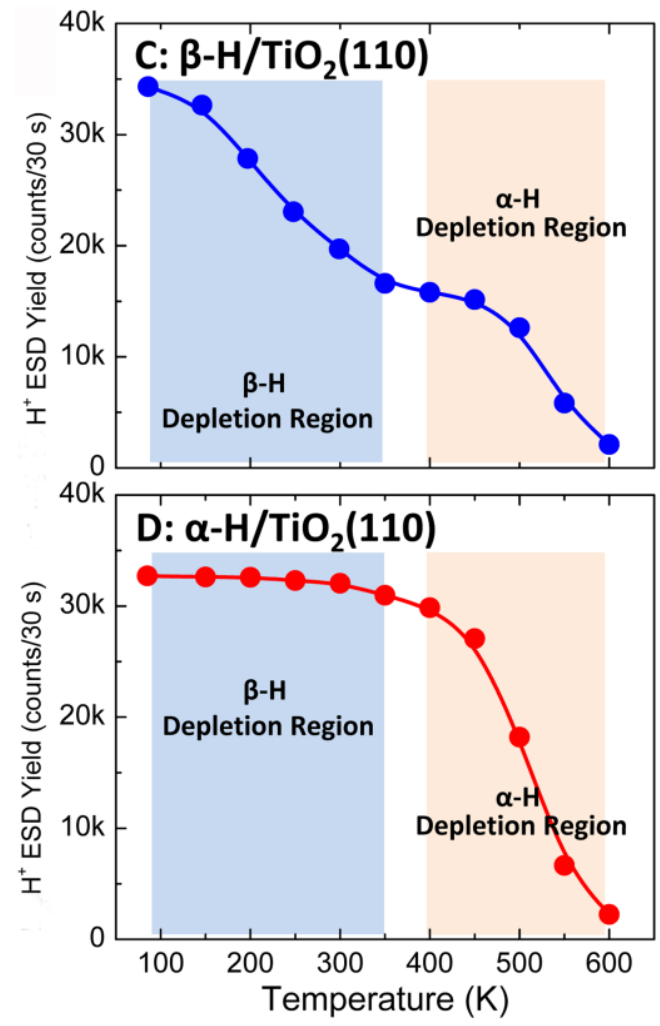

Figure 2. $\mathrm{H}^{+}$ESDIAD patterns on (A). $\beta-\mathrm{H} / \mathrm{TiO}_{2}$ and (B). $\alpha-\mathrm{H} / \mathrm{TiO}_{2}$ surfaces. In (A), the contribution of $\alpha-\mathrm{H} / \mathrm{TiO}_{2}$ is removed by thermal treatment of the surface based on the behavior shown in (C). (C). and (D). show the thermal depletion behavior of $\beta$ $\mathrm{H} / \mathrm{TiO}_{2}(110)$ and $\alpha-\mathrm{H} / \mathrm{TiO}_{2}(110)$ using integration of the TOF spectra of $\mathrm{H}^{+}$yields. 


\section{$\mathrm{H} / \mathrm{TiO}_{2}$ - ESD Cross Section Measurement}

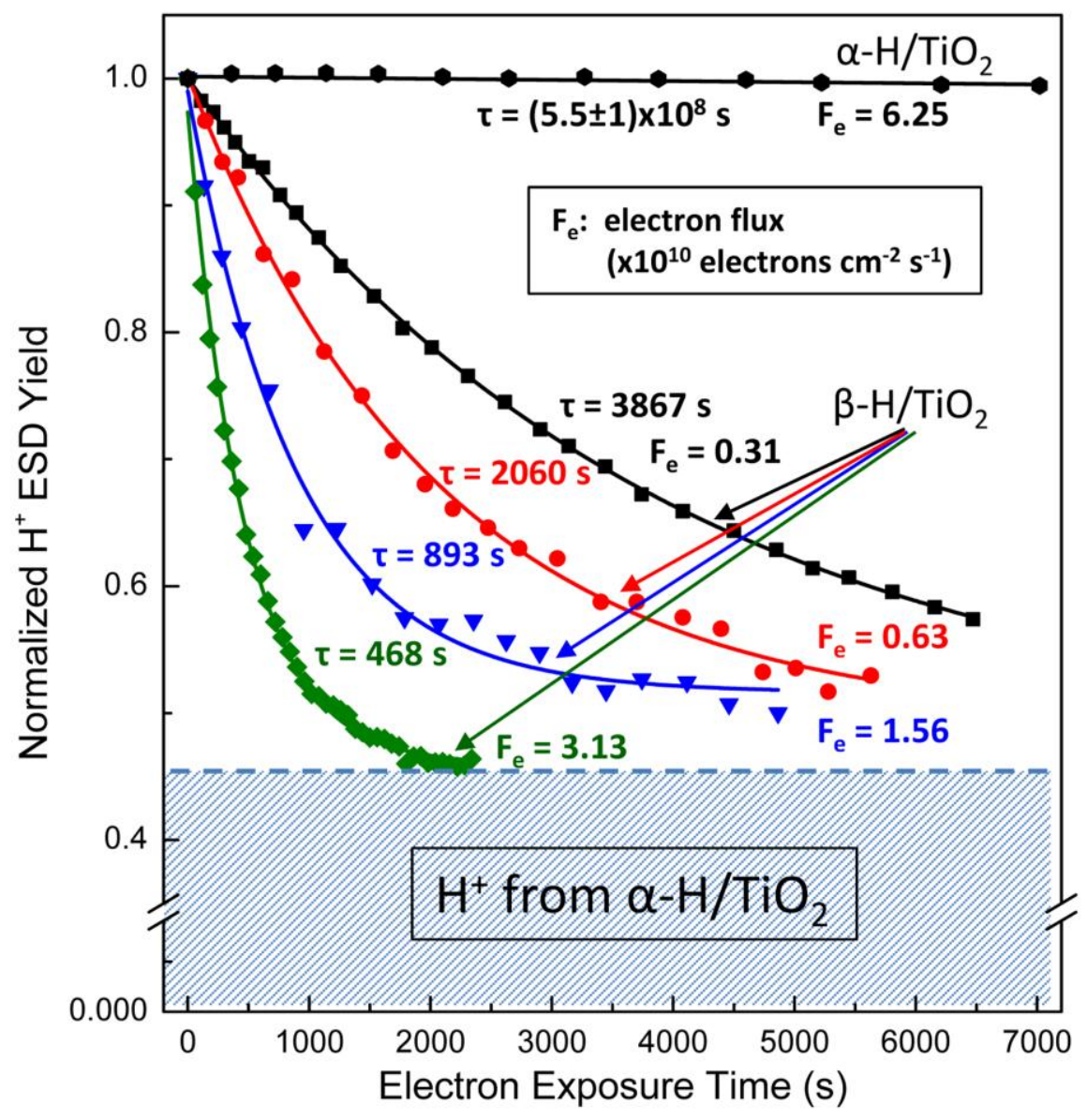

Figure 3. $\mathrm{H}$ species depletion by incident electrons with $210 \mathrm{eV}$ on $\alpha-\mathrm{H} / \mathrm{TiO}_{2}$ and $\beta$ $\mathrm{H} / \mathrm{TiO}_{2}$ species on $\mathrm{TiO}_{2}(110) .\left(\mathrm{Q}_{(\beta-\mathrm{H})}=\sim 7 \times 10^{-14} \mathrm{~cm}^{2}, \mathrm{Q}_{(\alpha-\mathrm{H})}=\sim 10^{-20} \mathrm{~cm}^{2}\right)$ 


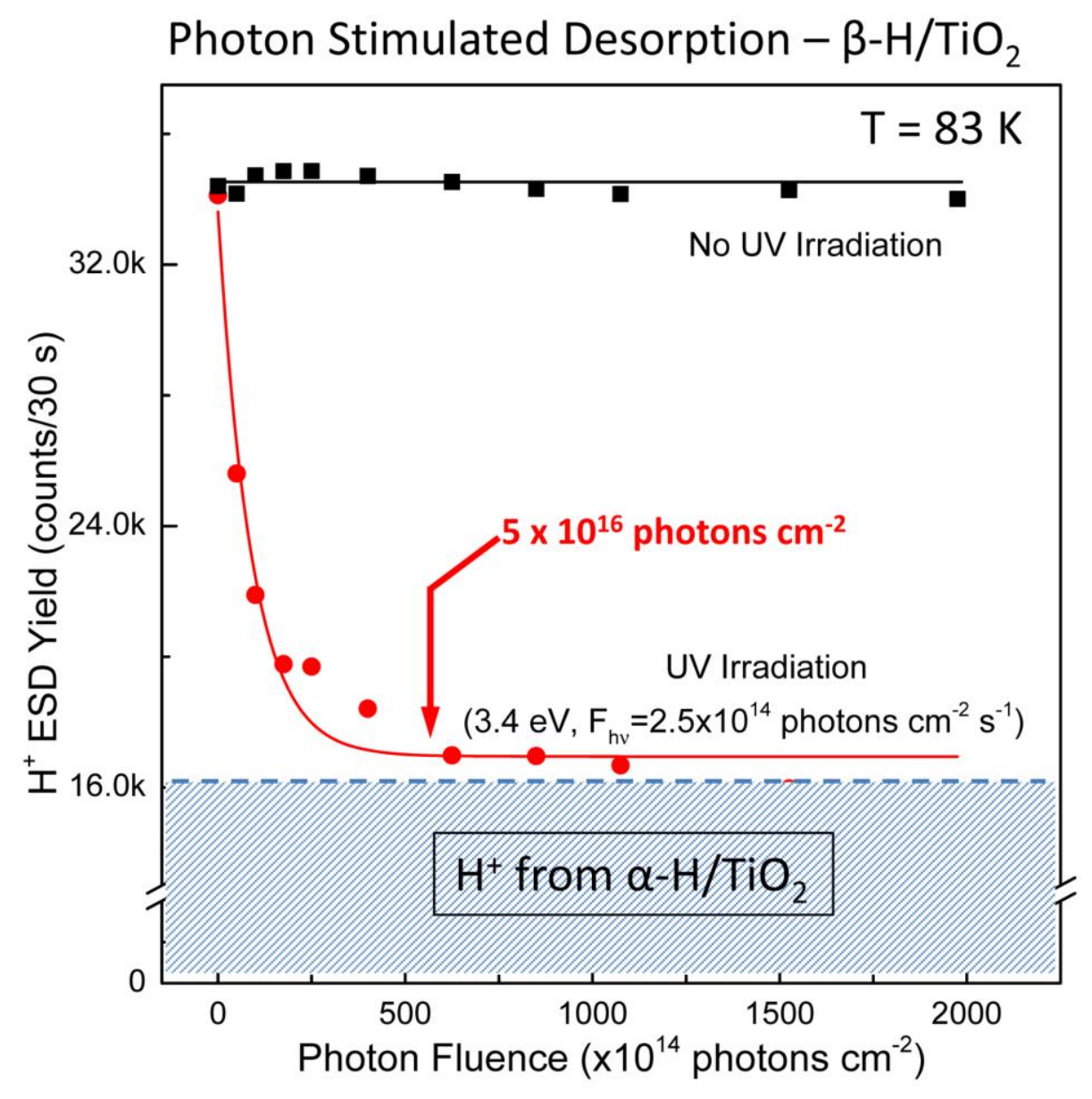

Figure 4 . $\mathrm{H}$ species depletion by incident UV photons $(3.4 \mathrm{eV})$ on $\beta-\mathrm{H} / \mathrm{TiO}_{2}$ measured by $\mathrm{H}^{+}$ESD yield. 

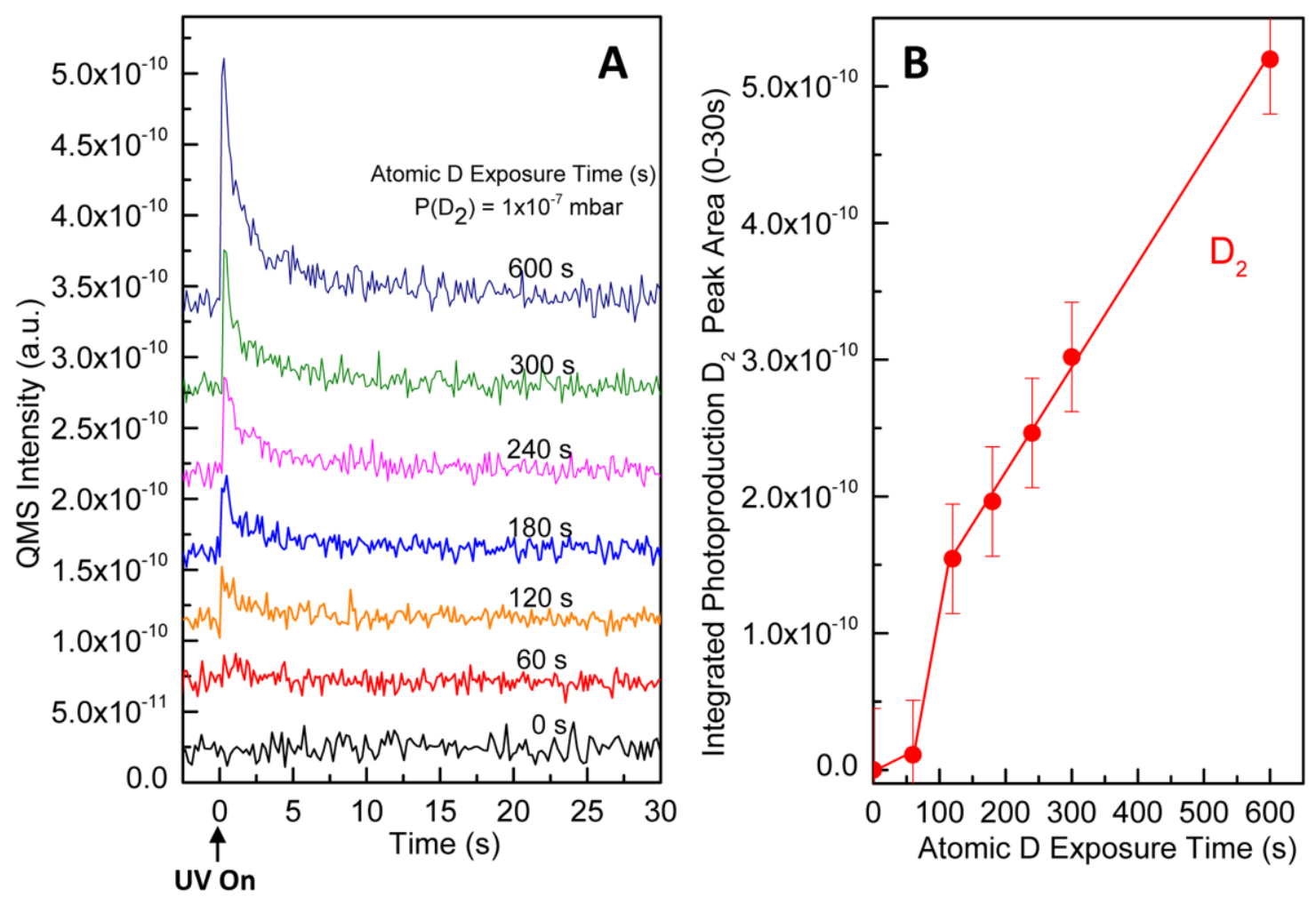

Figure 5. (A) QMS signal of $\mathrm{D}_{2}$ photo production on $\beta-\mathrm{D} / \mathrm{TiO}_{2}(110)$ surface upon UV irradiation (Hg lamp with IR filter,: 1.1-5.4 eV). (B). The evolution of the integration of $\mathrm{D}_{2}$ photo production yield at first $30 \mathrm{~s}$ after $\mathrm{UV}$ irradiation with atomic $\mathrm{D}$ exposing time. 


\section{References}

(1) Prins, R. Hydrogen Spillover. Facts and Fiction. Chem. Rev. 2012, 112, 2714-2738.

(2) Li, S. C.; Chu, L. N.; Gong, X. Q.; Diebold, U. Hydrogen Bonding Controls the Dynamics of Catechol Adsorbed on a $\mathrm{TiO}_{2}(110)$ Surface. Science 2010, 328, 882-884.

(3) Chen, X. B.; Liu, L.; Yu, P. Y.; Mao, S. S. Increasing Solar Absorption for Photocatalysis with Black Hydrogenated Titanium Dioxide Nanocrytals. Science 2011, 331, 746750.

(4) Liu, L.; Yu, P. Y.; Chen, X. B.; Mao, S. S.; Shen, D. Z. Hydrogenation and Disorder in Engineered Black $\mathrm{TiO}_{2}$. Phys. Rev. Lett. 2013, 111, 065505.

(5) McCluskey, M. D.; Tarun, M. C.; Teklemichael, S. T. Hydrogen in oxide semiconductors. J. Mater. Res. 2012, 27, 2190-2198.

(6) Kobayashi, Y.; Hernandez, O. J.; Sakaguchi, T.; Yajima, T.; Roisnel, T.; Tsujimoto, Y.; Morita, M.; Noda, Y.; Mogami, Y.; Kitada, A.; Ohkura, M.; Hosokawa, S.; Li, Z. F.; Hayashi, K.; Kusano, Y.; Kim, J. e.; Tsuji, N.; Fujiwara, A.; Matsushita, Y.; Yoshimura, K.; Takegoshi, K.; Inoue, M.; Takano, M.; Kageyama, $\mathrm{H}$. An oxyhydride of $\mathrm{BaTiO}_{3}$ exhibiting hydride exchange and electronic conductivity. Nature Mater. 2012, 11, 507-511.

(7) Habisreutinger, S. N.; Schmidt-Mende, L.; Stolarczyk, J. K. Photocatalytic reduction of $\mathrm{CO}_{2}$ on $\mathrm{TiO}_{2}$ and other semiconductors. Angew. Chem. Int. Ed. 2013, 52, 7372-7408.

(8) Fujishima, A.; Honda, K. Electrochemical Photolysis of Water at a Semiconductor Electrode. Nature 1972, 238, 37-38.

(9) Chen, X. B.; Liu, L.; Huang, F. Q. Black titanium dioxide $\left(\mathrm{TiO}_{2}\right)$ nanomaterials. Chem. Soc. Rev. 2015, DOI: 10.1039/C4CSO0330F

(10) Linsebigler, A. L.; Lu, G. Q.; Yates, J. T., Jr. Photocatalysis on $\mathrm{TiO}_{2}$ surface: Principles, mechanisms, and selected results. Chem. Rev. 1995, 95, 735-758.

(11) Thompson, T. L.; Yates, J. T., Jr. Surface Science Studies of the Photoactivation of TiO2 - New Photochemical Processes. Chem. Rev. 2006, 106, 4428-4453.

(12) Diebold, U. The surface science of titanium dioxide. Surf. Sci. Reports 2003, 48, 53-229.

(13) Henderson, M. A. A surface science perspective on TiO2 photocatalysis. Surf. Sci. Reports 2011, 66, 185-297.

(14) Henderson, M. A.; Epling, W. S.; Perkins, C. L.; Peden, C. H. F.; Diebold, U. Interaction of Molecular Oxygen with the Vacuum-Annealed $\mathrm{TiO}_{2}(110)$ Surface: Molecular and Dissociative Channels. J. Phys. Chem. B 1999, 103, 5328-5337.

(15) Yin, X.-L.; Calatayud, M.; Qiu, H.; Wang, Y.; Birkner, A.; Minot, C.; Wöll, C. Diffusion versus Desorption: Complex behavior of $\mathrm{H}$ atoms on an oxide surface. ChemPhysChem 2008, 9, 253-256.

(16) Wu, Z. F.; Zhang, W. H.; Xiong, F.; Yuan, Q.; Jin, Y. K.; Yang, J. L.; Huang, W. X. Active hydrogen species on $\mathrm{TiO}_{2}$ for photocatalytic $\mathrm{H}_{2}$ production. Phys. Chem. Phys. Chem. 2014, 16, 7051-7057.

(17) Kowalski, P. M.; Meyer, B.; Marx, D. Composition, structure, and stability of the rutile $\mathrm{TiO}_{2}(110)$ surface: Oxygen depletion, hydroxylation, hydrogen migration, and water adsorption. Phys. Rev. B 2009, 79, 115410.

(18) Wendt, S.; Matthiesen, J.; Schaub, R.; Vestergaard, E. K.; Lægsgaard, E.; Besenbacher, F.; Hammer, B. Formation and splitting of paired hydroxyl groups on reduced TiO2(110). Phys. Rev. Lett. 2006, 96, 066107. 
(19) Zhang, Z. R.; Bondarchuk, O.; Kay, B. D.; White, J. M.; Dohnalek, Z. Imaging water dissociation on $\mathrm{TiO}_{2}(110)$ : Evidence for inequivalent geminate $\mathrm{OH}$ groups. J. Phys. Chem. B 2006, $110,21840-21845$.

(20) Bikondoa, O.; Pang, C. L.; Ithnin, R.; Muryn, C. A.; Onishi, H.; Thornton, G. Direct visualization of defect-mediated dissociation of water on $\mathrm{TiO}_{2}(110)$. Nature Mater. 2006, 5, 189192.

(21) Henderson, M. A. An HREELS and TPD study of water on TiO2(110): the extent of molecular versus dissociative adsorption. Surf. Sci. 1996, 355, 151-166.

(22) Wendt, S.; Sprunger, P. T.; Lira, E.; Madsen, G. K. H.; Li, Z. S.; Hansen, J. Ø.; Matthiesen, J.; Blekinge-Rasmussen, A.; Lægsgaard, E.; Hammer, B.; Besenbacher, F. The role of interstitial sites in the Ti3d defect state in the band gap of titania. Science 2008, 320, 1755-1759.

(23) Schaub, R.; Thostrup, P.; Lopez, N.; Lægsgaard, E.; Stensgaard, I.; Nørskov, J. K.; Besenbacher, F. Oxygen vacancies as active sites for water dissociation on rutile $\mathrm{TiO}_{2}(110)$. Phys. Rev. Lett. 2001, 87, 266104.

(24) Zhang, Z.; Cao, K.; Yates, J. T., Jr. Defect Electron Spreading on the TiO2(110) Semiconductor Surface by Water Adsorption. J. Phys. Chem. Lett. 2013, 4, 674-679.

(25) Panayotov, D. A.; Yates, J. T., Jr. n-Type doping of TiO2 with atomic hydrogen observation of the production of conduction band electrons by infrared spectroscopy. Chem. Phys. Lett. 2007, 436, 204-208.

(26) Sezen, H.; Buchholz, M.; Nefedov, A.; Natzeck, C.; Heissler, S.; Di Valentin, C.; Wöll, C. Probing electrons in TiO2 polaronic trap states by IR-absorption: Evidence for the existence of hydrogenic states. Scientific Reports 2014, 4, 3808.

(27) Noei, H.; Qiu, H. S.; Wang, Y. M.; Muhler, M.; Wöll, C. Hydrogen loading of oxide powder particles: A transmission IR study for the case of zinc oxide. ChemPhysChem 2010, 11, 3604-3607.

(28) Chen, W. P.; He, K. F.; Wang, Y.; Chan, H. L. W.; Yan, Z. J. Highly mobile and reactive state of hydrogen in metal oxide semiconductors at room temperature. Scientific Reports 2013, 3, 3149.

(29) Suzuki, S.; Fukui, K.-i.; Onishi, H.; Iwasawa, Y. Hydrogen adatoms on $\mathrm{TiO}_{2}(110)-$ $(1 \times 1)$ characterized by scanning tunneling microscopy and electron stimulated desorption. Phys. Rev. Lett. 2000, 84, 2156-2159.

(30) Pan, J.-M.; Maschhoff, B. L.; Diebold, U.; Madey, T. E. Interaction of water, oxygen, and hydrogen with $\mathrm{TiO}_{2}(110)$ surfaces having different defect densities. J. Vac. Sci. Technol. A 1992, 10, 2470-2476.

(31) Ramsier, R. D.; Yates, J. T., Jr. Electron-stimulated desorption: Principles and applications. Surf. Sci. Reports 1991, 12, 246-378.

(32) Mišković, Z.; Vukanić, J.; Madey, T. E. Calculations of reneutralization effects in ESDIAD. Surface Science 1986, 169, 405-413.

(33) Yates, J. T., Jr.; Ahner, J.; Mocuta, D. Tracking the motion of chemisorbed molecules on their adsorption sites. Proc. Natl. Acad. Sci. USA 1998, 95, 443-449.

(34) Du, Y.; Petrik, N. G.; Deskins, N. A.; Wang, Z.; Henderson, M. A.; Kimmel, G. A.; Lyubinetsky, I. Hydrogen reactivity on highly-hydroxylated $\mathrm{TiO}_{2}(110)$ surfaces prepared via carboxylic acid adsorption and photolysis. Phys. Chem. Phys. Chem. 2012, 14, 3066-3074.

(35) Xu, C. B.; Yang, W. S.; Guo, Q.; Dai, D. X.; Chen, M. D.; Yang, X. M. Molecular hydrogen formation form photocatalysis of methanol on $\mathrm{TiO}_{2}(110)$. J. Am. Chem. Soc. 2013, 135, 10206-10209. 
(36) Tan, S. J.; Feng, H.; Ji, Y. F.; Wang, Y.; Zhao, J.; Zhao, A. D.; Wang, B.; Luo, Y.; Yang, J. L.; Hou, J. G. Observation of photocatalytic dissociation of water on terminal Ti sites of $\mathrm{TiO}_{2}(110)-1 \times 1$ surface. J. Am. Chem. Soc. 2012, 134, 9978-9985.

(37) Zhang, Z.; Yates, J. T., Jr. Direct Observation of Surface-Mediated Electron-Hole Pair Recombination in $\mathrm{TiO}_{2}(110)$. J. Phys. Chem. C 2010, 114, 3098-3101.

(38) Enevoldsen, G. H.; Pinto, H. P.; Foster, A. S.; Jensen, M. C. R.; Hofer, W. A.; Hammer, B.; Lauritsen, J. V.; Besenbacher, F. Phys. Rev. Lett. 2010, 104, 119604.

(39) Li, S. C.; Zhang, Z. R.; Sheppard, D.; Kay, B. D.; White, J. M.; Du, Y.; Lyubinetsky, I.; Henkelman, G.; Dohnalek, Z. Intrinsic Diffusion of Hydrogen on Rutile $\mathrm{TiO}_{2}(110)$. J. Am. Chem. Soc. 2008, 130, 9080-9088.

(40) Enevoldsen, G. H.; Pinto, H. P.; Foster, A. S.; Jensen, M. C. R.; Hofer, W. A.; Hammer, B.; Lauritsen, J. V.; Besenbacher, F. Imaging of the Hydrogen Subsurface Site in Rutile $\mathrm{TiO}_{2}$. Phys. Rev. Lett. 2009, 102, 136103.

(41) Calatayud, M.; Yin, X.-L.; Qiu, H.; Wang, Y.; Birkner, A.; Minot, C.; Wöll, C. Comment on "Image of the Hydrogen Subsurface Site in Rutile $\mathrm{TiO}_{2}$ ". Phys. Rev. Lett. 2010, 104, 119603.

(42) Akbulut, M.; Sack, N. J.; Madey, T. E. Elastic and inelastic processes in the interaction of 1-10 eV ions with solids: ion transport through surface layers. Surf. Sci. Reports 1997, 28, 177-245.

(43) Knotek, M. L. Characterization of Hydrogen Species on Metal-Oxide Surfaces by Electron-Stimulated Desorption: $\mathrm{TiO}_{2}$ and $\mathrm{SrTiO}_{3}$. Surf. Sci. 1980, 101, 334-340.

(44) Knotek, M. L.; Feibelman, P. J. Ion Desorption by Core-Hole Auger Decay. Phys. Rev. Lett. 1978, 40, 964-967.

(45) Panayotov, D. A.; Yates, J. T., Jr. Spectroscopic Detection of Hydrogen Atom Spillover from Au Nanoparticles Supported on $\mathrm{TiO}_{2}$ : Use of Conduction Band Electrons. J. Phys. Chem. C 2007, 111, 2959-2964. 
TOC Graphic

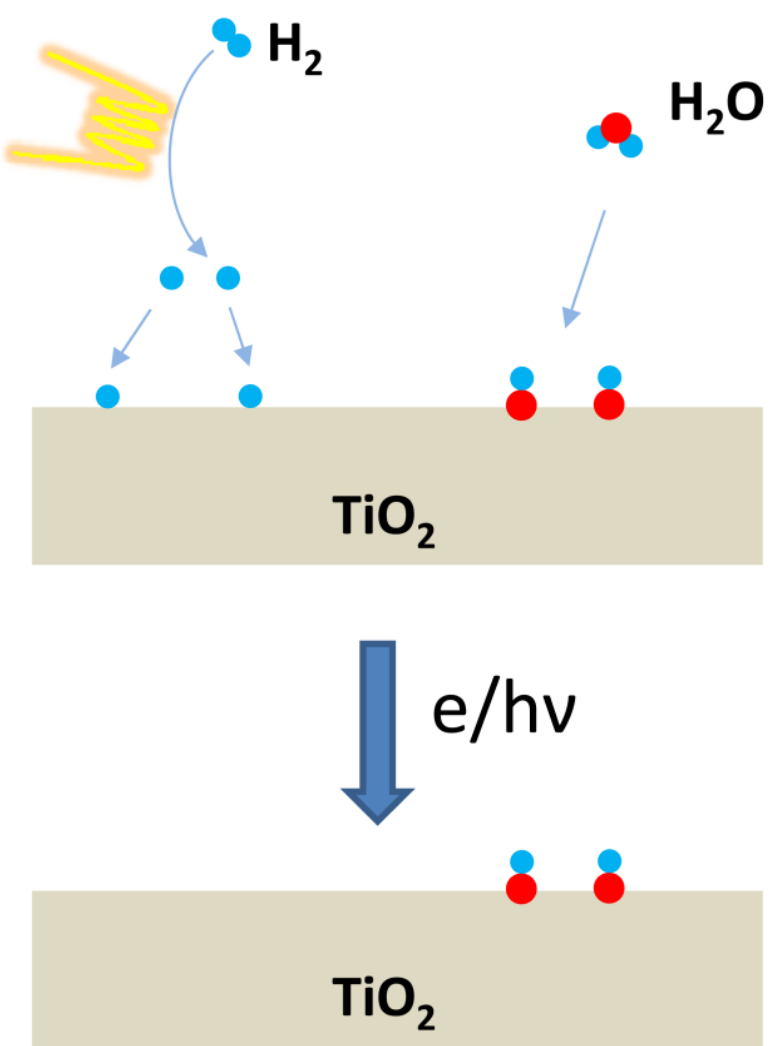

